\title{
To Oleg Shishkin
}

Zoia Voitenko ${ }^{\mathrm{a}}$ and Remi Chauvin ${ }^{\mathrm{b}}$

${ }^{a}$ Department of Chemistry, Taras Shevchenko National University of Kyiv, Volodymyrska St., 64/13, Kyiv 01601, Ukraine

${ }^{\mathrm{b}}$ CNRS, Laboratoire de Chimie de Coordination, 205 Route de Narbonne, 31077 Toulouse, France

The Editors of the just-born FrenchUkrainian Journal of Chemistry have the immense sadness to announce the loss of one of the most eminent and endearing members of its Editorial Board, Oleg Shishkin, who prematurely died in July 2014.

Prof. Oleg Shishkin was a renowned expert in various field of chemistry, ranging from organic chemistry to computational quantum chemistry, through crystallography. His scientific interests have addressed key issues in the understanding of the structures and properties of various molecules and materials, in particular through the study of conformational dynamics of organic molecules, and through the analysis of the nature of intermolecular interactions in molecular complexes and crystals. He propounded an innovative approach to the classification of supramolecular architectures of molecular crystals, based on the analysis of the topology and energy of intermolecular interaction.

As an author and co-author of more than 1,000 papers, Prof. Shishkin was one of the Top-20 most cited Ukrainian scientists. Oleg Shishkin was famous far beyond Ukraine's borders. This is evidenced by the extent of his

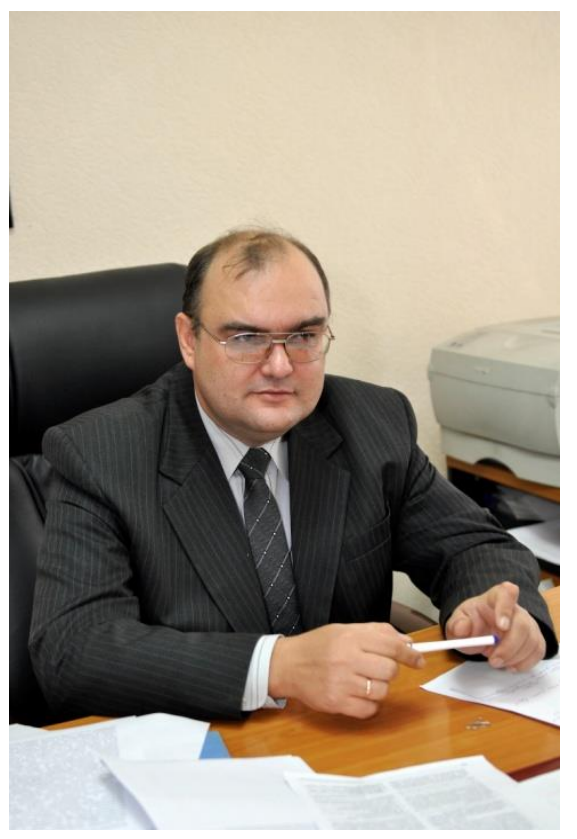

Dr. Sc. in Chemistry, Acting General Director of the SSI "Institute for Single Crystals" of the National Academy of Sciences of Ukraine, Head of the Department of X-ray Diffraction Studies and Quantum Chemistry, an extraordinary man - Prof. Oleg Valeryevich Shishkin who passed away at the age of 47 .

collaborative work, and by the number of conferences that he gave at international congresses.

With admirable enthusiasm, he created and organized the MACC symposia (Methods and Applications of Computational Chemistry), the latest MACC-5 event having been held in Kharkiv in 2013. He was also a regular participant of the so called "Toulouse-Kiev 
Conferences", and an active member of the

CNRS French-Ukrainian International Science.

Consortium in Molecular Chemistry

(Groupement de Recherche International en

Chimie Moléculaire).

Prof. Shishkin strongly believed in the popularization of science, and gave numerous related interviews to mass media. While giving updates on specific achievements and projects of the Institution to which he was responsible, he wrote landmark articles dedicated to the organizational improvement of scientific activities in contemporary conditions. As an adamant supporter of the Youth involvement in Science, he provided constant assistance to young researchers, trained many $\mathrm{Ph} . \mathrm{D}$. students, and ultimately had continued commitment to teaching at the V.N. Karazin National University of Kharkiv.

Wherever he was - in Kharkov, Kiev, Toulouse,... - everyone enjoyed to talk with him about scientific topics and about Science, or hear his opinion about the organization of cooperation at different levels. Leonardo da Vinci, another wise scientist, said "A happy life is a long life". But looking at the scientific way of Oleg Shishkin, one can confidently dare to add: "A happy life is also a productive, constructive, creative and recreative scientific life."

We lost a creative man, full of energy, ideas, erudition and professional enthusiasm. We also lost a friend, full of passion and heart. 